\title{
Effects of Bidding Data Disclosure on Unilateral Exercise of Market Power
}

\author{
Ali Darudi, Atefeh Zomorodi Moghadam, Hossein Javidi Dasht Bayaz \\ Electrical engineering department \\ Ferdowsi University of Mashhad \\ Mashhad, Iran \\ ali.darudi@gmail.com
}

\begin{abstract}
Disclosure and public availability of market related information is referred to as data transparency in electricity markets. There are still several open questions about the extent and quality of optimal market data transparency. Such concerns will be even more sever in emerging smart grids; although proper communication infrastructure facilitates data sharing and disclosure, market designers or microgrid operators should not publish data excessively as it might have negative effects on market integrity or consumers' privacy. In this paper, we propose a framework to quantitatively measure effects of transparency of bidding data of generating companies on unilateral exercise of market power and short term market price. Simulation results on an actual market (Alberta) indicate that inappropriate disclosure of bids allows generating companies to increase price impressively which in turn increases end user consumers' expenses. Accordingly, market designers should pay careful attention to their data transparency policies to avoid any kind of manipulations in the markets.
\end{abstract}

\section{INTRODUCTION}

\section{A. Problem definition and motivation}

Since 1980s, the electricity industries in several countries have been gradually changed from a monopoly into a deregulated market. In such a competitive environment, generating companies (GenCos) are required to bid (offer) their capacity to the market trying to maximize their profit while minimizing the risk of not being accepted. Successfulness of GenCo depends not only on its own internal variables (cost functions and bids), but also on external variables such as market status (demand and congestion) and rivals' bids. Therefore, timely and transparent availability of market data is necessary for the successfulness of an optimal biding strategy.

Public availability and disclosure of market related information is referred to as data transparency in electricity markets. Currently, in majority of electricity markets around the world, basic fundamental market data are publically published, including transmission capacities, forecasted demand, price, etc. However, the extent and quality of market data availability varies dramatically in different electricity markets depending on their respective independent system operator (ISO)'s policies; for instance, in different markets, bidding data of GenCos are available in different manners including: (i) not being published at all, (ii)being published with masked identities, (ii)being published with considerable delay (more than 1 month), (iii)being published with short delay (minutes or hours after market clearing), and (iv) being published within price bands instead of a specific price offer data. There are still several open questions about the extent and quality of optimal market data transparency. Such concerns will be even more sever in emerging smart grids; although proper communication infrastructure facilitates data sharing and disclosure, market designers or microgrid operators should not publish data excessively as it might have negative effects on market integrity or consumers' privacy.

When assessing and deciding about the right level of information to be disclosed, a difficult balance needs to be struck between negative and positive effects of transparency in electricity markets. There are several advantages regarding transparency of data in electricity markets, including:

- Providing an effective competitive environment: To compete fairly and effectively, all market participants, including GenCos, need to estimate future status of market, demand and supply conditions and transmission capacities. Furthermore, creating a perfect competition in electricity markets is one of the long desired goals of market designers and policy makers. Therefore, data transparency has been always important to market designers because, theoretically speaking, one of the main pre-requisite and conditions of a perfectly competitive market is the availability of data to all market participants.

- Reducing data asymmetry: Large GenCos have an information advantage over smaller market participants, as they can easily monitor their own production and offers which comprise a large portion of the market. Accordingly, if proper data transparency policies are not applied, an unlevel playing field will be created which 
potentially leads to manipulation of the market by the large GenCos. In other words, data transparency might prevent exercise of unilateral market power

- Reducing market risk and long term costs: Accurate information about the prices allow market competitors to make efficient decisions about supply and causes to increase their profits. Without such information, market risks will be increased and market participants make less efficient decisions which probably results in higher short term production costs and long term under/over investment. Although these consequences might cause the retail price to decrease in short term, retail price will eventually increase in long term to cover increased costs of production.

- Removing entrance barrier and increasing market liquidity: Transparent data about current and future status of the market provides investors with clear insight about the market, which probably encourages them to invest in the market. Furthermore, data asymmetry between market participants is a barrier to market entry as it discourages investors to enter an unfair market. Therefore, data transparency helps remove market entrance barriers which subsequently lead to increases in market liquidity.

- Improved market monitoring: Availability of market data allows monitoring and surveillance of the market to regulators as well as academics and the general public. Such monitoring of market possibly leads to identifying market abuse and exercise of market power.

Although public transparency of data is generally assumed to improve market outcomes, excessive disclosure of market data may have severely adverse effects on market. One of the most valid such concerns is facilitating exercise of market power. Market power is defined as the ability of producers to increase market clearing price over marginal cost by withholding their product. Hence a producer can raise its profit by reducing the amount of its product which results in higher prices in electricity market. Excessive disclosure of market data raises the following concerns:

- Coordinated behavior among suppliers (multilateral market power): Excessive data disclosure provides GenCos with wide and similar information about market which might facilitate coordinated behavior. Moreover, participants in collusion might simply identify participants deviating from their previous agreements and punish them accordingly. In general, coordinated behavior can result in a variety of harms including high retail prices for consumers and reducing market competitiveness. Actually, potential for suppliers to engage in anti-competitive coordination was one of the reasons that ISO prefers to disclose data with delay.

- Unilateral Exercise of market power: The potential and ability of a large GenCos to exercise (unilateral) market power depends not only on its own features (such as capacity, cost and location in network), but also on market conditions and rivals' behavior. Therefore, providing GenCos with detailed information about market and competing firms possibly enhance the ability of GenCos to exercise market power more effectively. For instance, GenCos might adjust their bidding strategies to exercise market power by forecasting rivals' bidding behavior

Given abovementioned advantages and disadvantages regarding market data transparency, there are still lots of discussions about the proper policies for data disclosure. For instance, market surveillance administrator (MSA) of Alberta electricity market considers revising its data disclosure policies [1]. In particular, there have been arguments about appropriate conventions for disclosure of bidding (offer) data in different markets including Alberta [1], Italy [2] and Singapore [3]. In this paper, we investigate effects of disclosing actual bidding (offer) data with very short time delays.

As mentioned earlier, availability of rivals' offers lets a certain GenCo exercise market power. More precisely, ideally speaking, a price making GenCo requires calculating its residual demand to develop an appropriate bidding strategy that can effectively take into account its ability to alter market price. Residual demand curve (also known as quota curve) of a GenCo for a given hour provides the market clearing price as a function of the GenCo's production[4]. Residual demand is defined as the demand minus the aggregate supply offers of all other GenCos[5]. Therefore, disclosure and availability of offer data provides the opportunity to exercise unilateral market power. In this paper, we propose a framework to quantitatively measure effects of transparency of offer data on unilateral exercise of market power and short term market price.

\section{B. Literature review}

The residual demand has been widely used by economists and researchers to analyze strategic behaviors in oligopolistic markets, such as electricity markets[6]. In fact, one of the popular approaches for measuring exercise or potential of unilateral market power is to analyze residual demand curve of GenCos. Wolak investigates the ability of the five largest GenCos in the California's balancing market (CAISO) to exercise market power in 1998 to 2001[7]. He calculates the ex-post hourly residual demand elasticity for each firm based on actual bid data. Residual demand elasticity quantifies the extent to which the GenCo is able to raise the hourly price by 
reducing its generating power. In[8], McRae and Wolak apply the same procedure on New Zealand electricity market. Based on a supplier's residual demand curves, they present two indices to measure ability and incentive of the supplier to exercise market. Then, they show that market prices are highly correlated with the measures of both the ability and incentive of the four large suppliers in New Zealand to exercise market power. Similarly, residual demand curve is used in investigating unilateral market power exercise in several other markets including Italy [2] and Iberian market [9]. All these methods are ex-post analysis. A critique of such residual demand based approaches is that they do not consider the costs involved with a firm exercising unilateral market power. We consider generation cost in our investigations.

\section{Contributions}

In this paper, we propose a framework and an index to quantitatively measure effects of disclosure of offer data on exercising unilateral market power in a pool market with uniform pricing mechanism. We assume that data transparency policies of the target market allow disclosure of bid (offer) data very close to the bidding time. Accordingly, a certain price maker GenCo can predict bids of the rival companies with high accuracy using time series methods. An equivalent situation is that a certain GenCo hacks into the operators systems and obtains bidding data of its rivals. As a result, the GenCo is able to estimate its hourly residual demand for each hour of the next day and submit strategic bids accordingly. Obviously, we expect that such strategic bidding results in higher profit for the GenCo as well as higher market price, compared to the situation in which GenCo nonstrategically bid its marginal cost to the market.We are able to quantitatively measure effects of such market data disclosure on market status by comparing resultant market price in the strategic bidding scenario with that of the non-strategic bidding (marginal cost bidding that does not require any external data such as residual demand). We also define an index to measure such market price increase caused by offer data disclosure. Furthermore, qualitatively speaking, it is also expected that larger generating companies are able to exercise greater market power. We also quantitatively evaluate the validity of this expectation by applying the above mentioned procedure for GenCos with different total generating capacities.

The rest of the paper is organized as follows: Section II describes the proposed framework. Section III presents two different bidding strategies used in the proposed framework. Section IV is devoted to numerical results and discussion. Finally, the paper is concluded in section V.

\section{FRAMEWORK}

In this paper we try to express how data disclosure might result in exercise of unilateral market power, and accordingly, how market clearing price and the profit of producers might increase. The structure of electricity market is considered as pool-co with uniform clearing mechanism.

Our approach to solve this problem consists of six steps: 1) Select a price maker producer with a specific cost function. 2) Disclose the market offer and demand data for the GenCo to calculate residual demand. 3) Develop non-strategic bids based simply on marginal cost. 4) Assume another situation in which the GenCo bids strategically based on the hourly residual demand curves. 5) Compare the market clearing price and the profit of GenCo of these two strategic and nonstrategic bidding scenarios.

Details of each step are described in the following: In step 1 , choosing only one GenCo implies that we measure effects of offer data disclosure on unilateral exercise of market power, as opposed to multilateral market power. It is essential to know the cost function of the GenCo as it plays an important role in profit maximization procedure.

In step 2, we provide essential data for the price maker GenCo to bid strategically later in step 4. As mentioned earlier, a price making producer can use residual demand curves to bid strategically and exercise unilateral market power. However, to calculate hourly residual demand curves, one requires offer data of the rival companies and market demand. We assume that such data can be forecasted with high accuracy by the price maker. This could be a realistic assumption especially in markets that offer data are disclosed so close to real-time that a proper short term forecasting procedure might be used to accurately predict future offers of the rivals. To improve validity of our final results, we use offer data of an actual electricity market (Alberta).

In steps 3 and 4 , we calculate outcomes of the market (price and benefit of the GenCo) regarding applying two alternative bidding strategies. The main difference of these two methods is whether offer data of the rivals are available or not. In the first scenario, step 3, we assume that the GenCo does not have any specific data about the market status and rivals offer data, and consequently, it cannot exercise market power. Therefore, the GenCo simply submit its marginal cost to the market. It should be noted that marginal cost bidding requires no specific data, except the cost function of the GenCo (details of this bidding method are explained in the next section). On the other hand, in the second scenario, i.e. step 4, we assume that the GenCo access to (accurate prediction of) offer data and residual demand curves, and consequently, it is able to bid strategically and exercise market power (details of this bidding strategy method are explained in the next section). This scenario demonstrate oligopolistic nature of electricity markets more realistically as it allows the GenCo to consider effects of its own offers on market price. It is obvious that this bidding method requires more input data which can be available if proper data transparency policies are applied in the market. 
In step 5, we compare the outcome of the market (price, generation and benefit of the GenCo, etc.) for the two abovementioned scenarios described in steps 3 and 4. In fact, we compare the effect of availability of (accurate predictions of) offer data on ability of the test GenCo to exercise market power. To facilitate this comparison, we also propose an index to quantitatively measure the effects of offer data disclosure on market price increase. The index is defined as below:

$$
\text { Market Price Increment }=\frac{\text { price }_{\text {residual demand }}}{\text { price }_{\text {marginal cost }}}
$$

The higher the market price increment (MPI) index value becomes, the more intensive the effect of market data disclosure is. It can be proved that MPI index is always equal or greater than 1. In other words, we expect that the strategically bidding based on availability of residual demand curves data (oligopolistic market) leads to greater prices compared with marginal cost bidding (perfect competition).However, the extent of market price increase (value of the MPI index) depends on rivals' offers, market demand, residual demand curves and cost function of the price making GenCo. In step 5, we can measure this increase quantitatively.

\section{BIDDING STRATEGIES}

\section{A. Marginal cost}

GenCos which do not have the ability to exercise market power might simply bid their marginal costs to the market as follows:

$\operatorname{bid}(\mathrm{q})=\operatorname{MC}(\mathrm{q})=\frac{\partial c(\mathrm{q})}{\partial q}$

Where $q$ denotes GenCo's quantity of generation, $\operatorname{bid}(q)$ denotes the submitted price for producing $q$. $M C$ stands for marginal cost. In step 3 of the framework, we assume that the GenCo bids its marginal cost to market in all 24 hours of the day-ahead market.

\section{B. Residual demand curve based}

The bidding strategy of the price maker GenCo that we use in step 4 is based on residual demand curves. We adopt a mixed integer linear programming (MILP) approach to calculate optimal bidding strategy in day-ahead market mathematical which is mostly inspired form[4].

Mathematically speaking, residual demand for a certain GenCo is defined as:

$$
R D_{t}(\mathrm{q})=d_{t}(\mathrm{q})-\mathrm{S}_{i-1, t}(q)
$$

Where $R D$ stands for residual demand and $t$ denotes the time step. Moreover, $d_{t}(q)$ and $S_{i-1, t}(q)$ denote market demand and aggregate offer curve of the rival companies, respectively.
The objective is to find 24 pairs of price and quantity $\left(p_{t}, q_{t}\right)$ that maximize the profit of a price making GenCo in day-ahead market. Generally, the profit equals total revenue minus total production cost. This formulation is:

$$
\underset{p_{t}, q_{t}}{\operatorname{Maximize}} \sum_{t=1}^{T}\left[\lambda_{t}\left(q_{t}\right) q_{t}-c_{t}\right]
$$

Where $q_{t}$ is the produced power by GenCo, and $\lambda_{t}$ is its corresponding price which is obtained from residual demand curve. The first term of the objective function is the total revenue and the second one denotes the total production cost. The problem is non-linear due to the products between the variables in the objective function. As finding solutions for nonlinear problems might result in solutions which are not globally optimal, the problem needs to be redefined into a linear problem. The linearization procedure of this formulation is similar to what expressed in [4].

\section{NUMERICAL RESULTS AND DISCUSSION}

This section presents the results of applying the proposed framework for measuring the effects of bidding data disclosure on ability of a GenCo to exercise unilateral market power. To improve the validity of our results, an actual electricity market, Alberta's market, has been chosen as the case study. In other words, we have used GenCo's bidding data and network demand of Alberta's electricity market to create residual demand curves. The first week of February 2010 (February 1 to 6) is chosen as the test week. It is supposed that GenCo's participate in a day-ahead market. Moreover, market clearing mechanism is uniform.

\section{A. Alberta's market}

Alberta's electricity market is an energy-only, real-time market with uniform clearing mechanism. In Alberta, the installed generation capacity and the average annual demand are approximately 13,000 MW and $8000 \mathrm{MWh}$, respectively[10]. Market clearing procedure does not consider transmission constraints directly. While Alberta's demand is relatively periodic, price is highly volatile and price spikes are not uncommon in the market (Fig. 1).

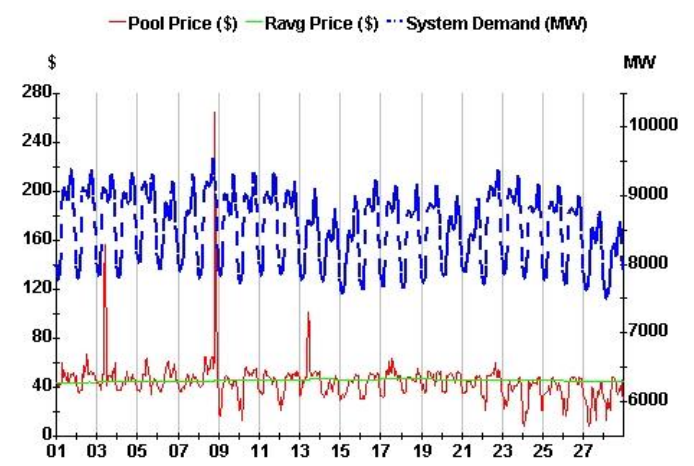

Figure1. Alberta's electricity market price and demand in February 2010, $\mathrm{X}$-axis: day in month[10] 


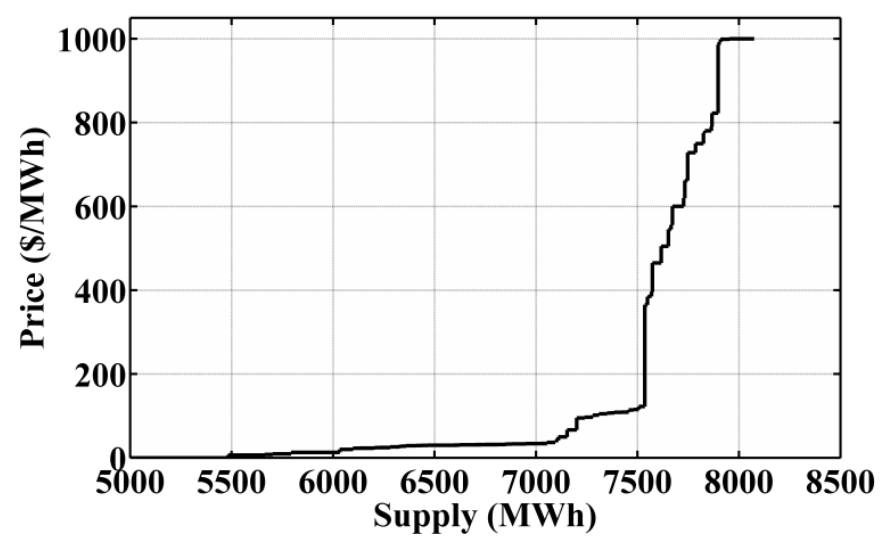

Figure2. Typical aggregate supply curve of Alberta electricity market (May 1,2010 , hour ending in 19).

Fig. 2 illustrates some interesting features of a typical aggregate supply curve (ASC) in Alberta's market. Significant amount of the power (in this case, about $60 \%$ of the total capacity of the market) is offered at the price of zero. This phenomenon is the case that happens in markets with uniform clearing mechanism. In such markets, all generating companies are paid with the market clearing price, regardless of their own bids. As a result, generating companies, particularly the ones with high start-up costs, offer all or a major part of their capacity at zero price to avoid the risk of losing in the market. The rest of the ASC can be described as a "hockey stick"-shaped curve: moderate slope region followed by a very steep slope toward the end. Finally, the last portion of the supply is offered as high as $1000 \$ / \mathrm{MW}$ (market price cap). It should be noted that, Alberta electricity market, wind generators do not bid to the market and their generation are directly fed to the network. In other words, the wind generation might be simply regarded as a negative demand.

\section{B. Generating companies}

It is believed that a GenCo's capacity plays an important role in the extent they can exercise market power. Therefore, to evaluate this hypothesis, we have repeated our framework three separate times; in each time, effects of bidding data disclosure to a certain GenCo, with a certain capacity, is evaluated. For the sake of simplicity, it is assumed that each GenCo owns only one generating unit. Capacity and characteristics of the test units (GenCos) are presented in Table I. Cost function is assumed to be quadratic. Fig. 3 compares cost functions of the test Gencos.

Total market capacity might also affect market power. It should be noted that as in each test case we manually add a certain generating unit to the original Alberta market, total market capacity increases which might affect market power of the GenCo. Actually, in each round of the procedure, we add a unit with a different capacity. Therefore, it might be inferred that results of the three repetitions are not comparable as
TABLE I. GENERATING UNITS DATA

\begin{tabular}{|c|c|c|c|}
\hline Max capacity [MW] & 100MW & $200 \mathrm{MW}$ & $300 \mathrm{MW}$ \\
\hline Min generation [MW] & 25 & 68.95 & 140 \\
\hline \multicolumn{4}{|l|}{ Cost coefficients } \\
\hline a (quadratic) $\left[\$ / \mathrm{MW}^{2}\right]$ & 0.035 & 0.0049 & 0.01 \\
\hline $\mathrm{b}\left(1^{\mathrm{st}}\right.$ degree $)[\$ / \mathrm{MW}]$ & 30.56 & 33.95 & 30.99 \\
\hline c (fixed) [\$] & 547.064 & 582.92 & 1795.77 \\
\hline Ramp rate $[\mathrm{MW} / \mathrm{h}]$ & 100 & 180 & 120 \\
\hline Shot down cost [\$] & 1635 & 2239 & 10190 \\
\hline Min up-time [h] & 8 & 12 & 24 \\
\hline Min down-time [h] & 8 & 10 & 48 \\
\hline
\end{tabular}

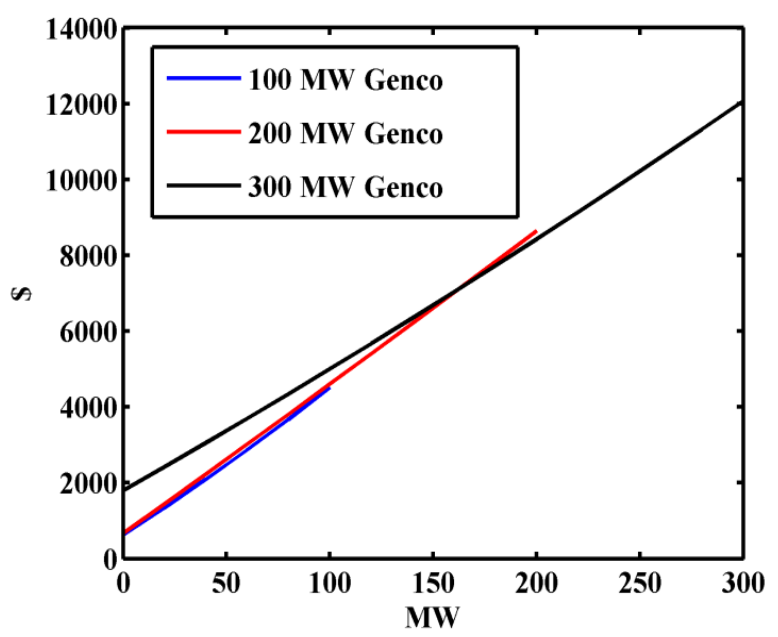

Figure 3. Cost curves of the test GenCos

market participants are facing markets with different total installed capacity. To prevent such problems, as we add a certain unit to the market at each test round, we also manually removed bids of a GenCo with similar capacity from the residual demand curves. Therefore, total market capacities in all repetitions are the same as each other (and also similar to the original capacity of Alberta electricity market). As a result, output results of the test cases can be compared with each other.

\section{Simulation results}

Figure 4 compares the accepted quantities of residual demand based bidding (in which bidding data of the competitors are available) and marginal cost bidding (in which the bidder does not have information about the market) in the market during the test week. As clearly shown, offered quantities of residual demand based biddings are always lower than or equal to those of the marginal cost bidding. For instance, in the case of $300 \mathrm{MW}$ generator, if marginal bidding approach is applied, the GenCo is usually dispatched to its 

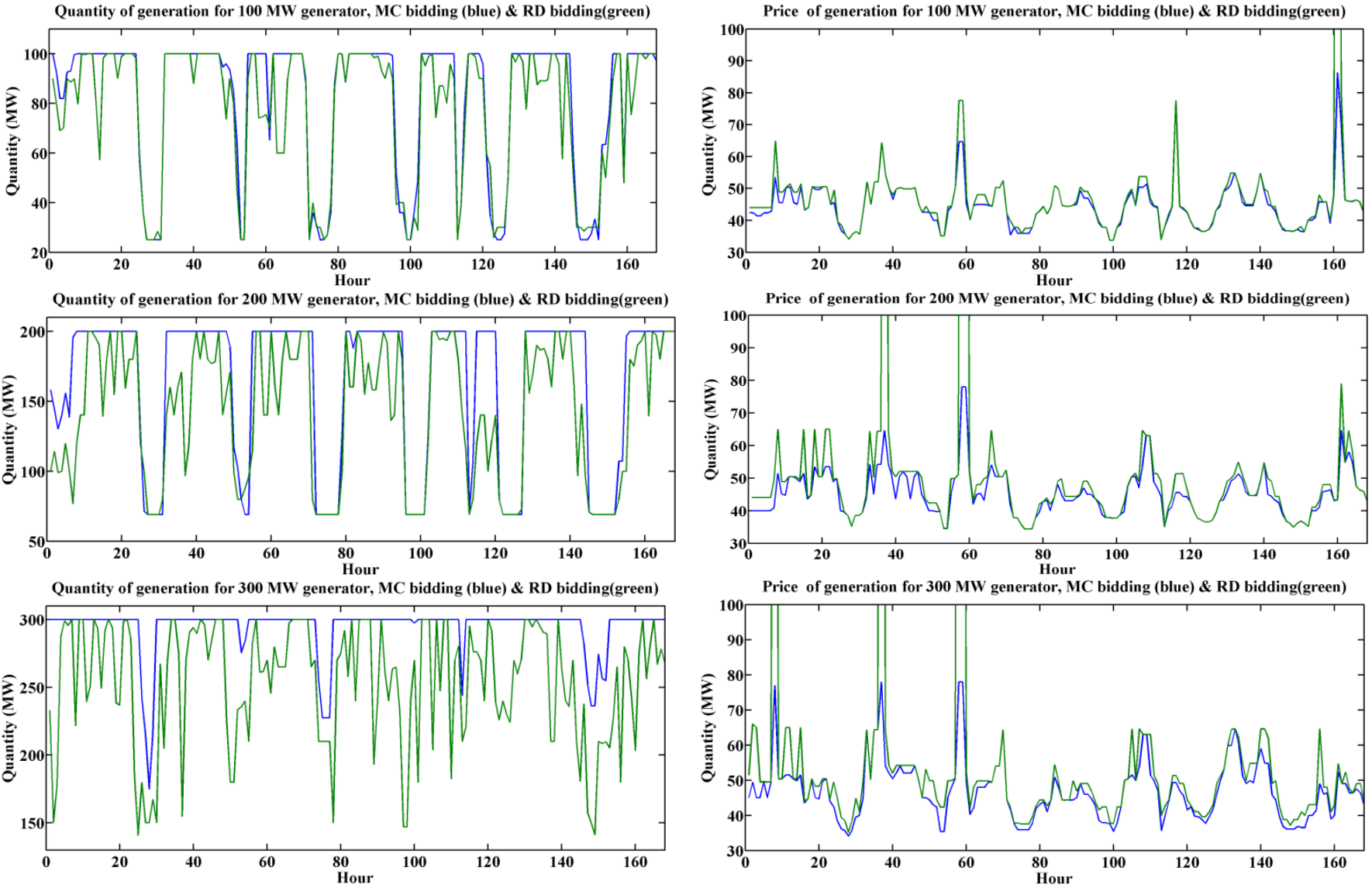

Figure 4. Accepted generation quantities in the market, comparison of marginal cost (MC) bidding and residual demand based (RD) bidding

maximum capacity by the market operator; while in the case of applying residual demand bidding approach, the accepted (dispatched) quantities are rarely the maximum capacity. It shows that market participants with market power and enough knowledge usually tend to withhold their capacity while bidding to the market. Their main motivation for withholding capacity is to increase the market price and accordingly their profit.

Fig. 5 illustrates market price resulted from the two bidding approaches in all the three case studies (generator). As expected, market price in the residual demand based bidding is always greater than or equal to that of marginal cost bidding. As a result, our proposed MPI index is always greater than or equal to 1. Fig. 6 demonstrates evolution of MPI index throughout the test week for the three test case GenCos. An interesting observation in Fig. 6 is that while MPI is usually varying between 1 to 1.2 , occasionally, it rises up as high as 9 which indicates that if only one GenCo has enough knowledge about the offers of the competitors (and apply residual demand curve bidding), it might increase market price up to 9 times

Figure5. Final market price for the test scenarios comparison of marginal cost (MC) bidding and residual demand based (RD) bidding.

greater than the case in which this specific GenCo use marginal cost bidding approach. This result seems even more interesting by considering the fact that our test generators' capacities (100MW or $200 \mathrm{MW}$ or $300 \mathrm{MW}$ ) are only a small portion of the total bade capacity (about $8000 \mathrm{MW}$ ). This suggests that in certain circumstances, even relatively small GenCos might be able to exercise considerable market power.

Fig. 6 also illustrates that the higher the capacity of the test GenCo is, the more and the larger the spikes become. In each test case, number of spikes in the MPI index differs in the test week. More precisely, 1, 3 and 4 spikes are observed in 100MW, 200MW and 300MW cases, respectively. MPI index spikes of the 200MW GenCo has occurred in $37^{\text {th }}, 58^{\text {th }}$ and $59^{\text {th }}$ hours. In the hour, $300 \mathrm{MW}$ test GenCo also demonstrates spikes, but with higher values. In these cases, the larger the capacity of the test GenCo is, the higher the value of the spikes become. In addition to the previous hours, 300MW test GenCo also shows a spike in the $8^{\text {th }}$ hour. These results support the theoretical expectations that GenCos with higher capacities are able to exercise higher market power. 


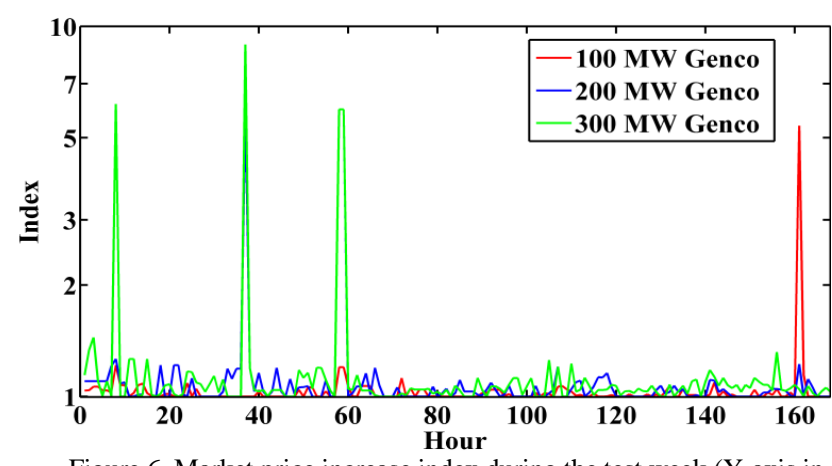

Figure 6. Market price increase index during the test week (Y-axis in logarithmic).

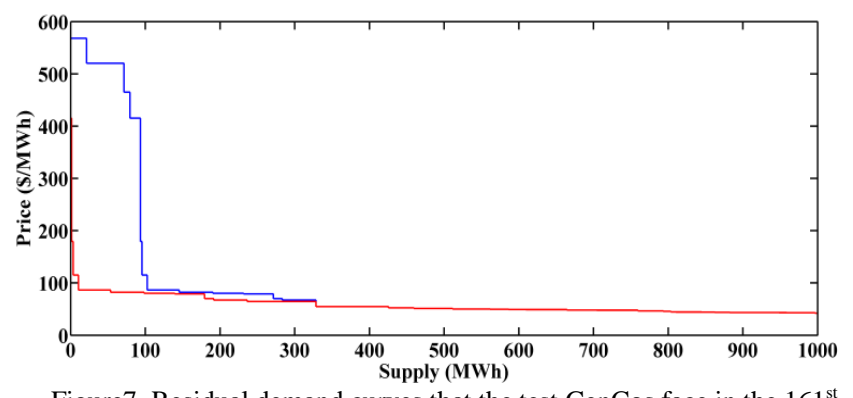

Figure7. Residual demand curves that the test GenCos face in the $161^{\text {st }}$ hour, (blue for the 100MW GenCo and red for 200MW GenCo).

A peculiar phenomenon is happening in the $161^{\text {st }}$ hour in which an MPI index spike occurs in the case of 100MW test GenCo (the smallest test GenCo) while other test GenCos do not show such spikes. This phenomenon is against common belief that higher capacities always are able to exercise higher market power. Although lower cost function of the 100MW could be the reason, in this specific hour, residual demand curves are the actual reason. Fig. 7 compares residual demand curves of that $100 \mathrm{MW}$ and $200 \mathrm{MW}$ test GenCos are facing in the $161^{\text {st }}$ hour. Obviously, residual demand curve of the 100MW GenCo provides more flexibility to manipulate market and increase market price.

Disclosure of bidding data and using them in bidding procedures increase -their short term- profits of all the generating companies. Fig. 8 compares GenCos profits obtained from applying the two bidding approach for the three test GenCos (100MW, 200MW and 300MW GenCo). Results indicate that applying residual demand approach, provided that basic input data such competitors' bids and demand is available, results in higher profits for the GenCo with market power in all the three cases. For instance, using residual demand based bidding, 300MW GenCo has earned 2.3times greater profit compared to applying marginal cost bidding.Furthermore, GenCo with higher capacity earns more profit which makes sense as their higher profits should compensate for their higher capital costs.

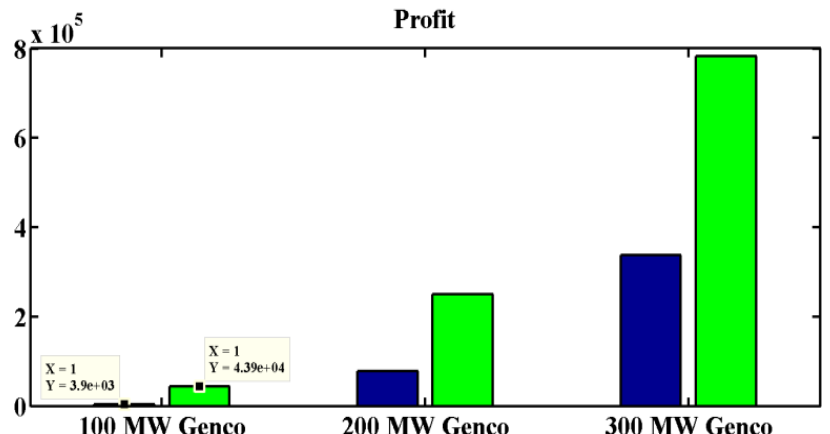

Figure8. Total profit of the target GenCo, comparison of marginal cost bidding profit (blue) and residual demand based bidding profit (green).

Interestingly, by exercising market power from only a certain test GenCo all other GenCos enjoy earning higher profits. Exercising market power increases market price and, in uniformly cleared markets, all the rest of the market participants are paid with this amount. Consequently, incomes of all GenCos increase. On the other hand,the quantity of their generation does not vary compared to the case that the test GenCo only bids its marginal costs. Therefore, their generation costs are the same in both scenarios. Consequently, given the increased income and similar costs, all the GenCos enjoy earning higher profits in the case of exercising market by only one GenCo. This might imply that if a certain GenCo exercise market power, other GenCos probably are not motivated to vary their bidding behavior, at least in short term.

Although exercising market power from a certain GenCo is beneficial for all GenCos, it has inverse financial effect on consumers as it imposes considerable financial burden on them by increasing market power.Fig. 9 compares the total expenses that should be paid to GenCos for satisfying demand. In fact, in each test case, the difference between the blue bar and the green bar illustrates the extra expense that consumers should pay if bidding data are somehow available to a certain GenCo. These expenses should be ultimately paid by consumers. As Fig. 9 clearly demonstrates, if market bidding data are somehow available to a certain GenCo, the total market expenses increases which ultimately means that the average cost of each $\mathrm{MWh}$ for the consumers rises.More precisely, the ratio of market expenses for the two bidding scenarios (residual demand curve based bidding versus marginal cost bidding) in the three test cases of $100 \mathrm{MW}$, 200MW and 300MW GenCos is 1.07, 1.20 and 1.29, respectively. It means that, for example, in the test case of 300MW test GenCo, if the GenCo exercises market power (as a consequence of availability of the bidding data), consumers should pay 1.29 times costs compared to the case that the GenCo simply bids its marginal cost. Therefore, evidently, at least in this case, increase in the market expenses is proportional to the capacity of the GenCo with market power. 


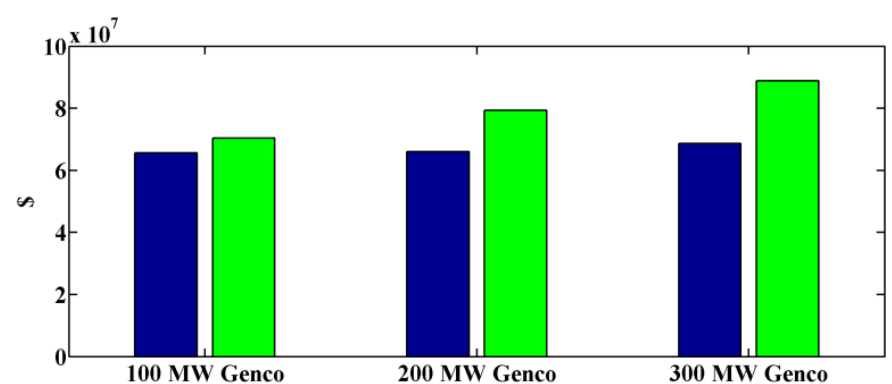

Figure 9. Total market expenses incurred by all the consumers in the test week, comparison of marginal cost bidding (blue) and residual demand based bidding (green).

\section{CONCLUSION}

In this paper, possibly negative effects of inappropriate data transparency policies are investigated. In particular, we measured the inverse effects of inappropriate disclosure of generating companies' bids on facilitating exercise of unilateral market power and the consequent market price increase. Simulation results on an actual market indicate that inappropriate disclosure of bids allows GenCos to increase price impressively which in turn increases end user consumers' expenses. Accordingly, market designers should pay careful attention to their data transparency policies to avoid any kind of manipulations in the markets. Similarly, although smart grid environments provide proper infrastructure to share data, data sharing protocols should be carefully designed so as to preclude any kind of manipulations whether unilaterally or coordinately.

Future works might address effects of bidding data disclosure on coordinated behavior of GenCos (tacit collusion) as well as the effects of uncertainty of future rivals' bids on exercising market power. Transmission constraints might also be considered.

\section{REFERENCES}

[1] A. Baziliauskas, M. Sanderson, and A. Yatchew, "Electricity Market Data Transparency Prepared for: Alberta Market Surveillance Administrator," 2011.

[2] C. A. Bollino and P. Polinori, "Measuring Market Power in Wholesale Electricity Italian Market," 2008.

[3] "Review of Market Information to Facilitate Efficient Electricity Spot and Future Trading, Consultation Paper," 2014.

[4] S. De Torre, J. M. Arroyo, A. J. Conejo, and J. Contreras, "Price Maker Self-Scheduling in a Pool-Based Electricity Market: A Mixed-Integer LP Approach," IEEE Trans. Power Syst., vol. 17, no. 4, pp. 1037-1042, 2002.

[5] L. Xu, S. Member, and R. Baldick, "TransmissionConstrained Residual Demand Derivative in Electricity Markets," IEEE Trans. Power Syst., vol. 22, no. 4, pp. 1563-1573, 2007.
[6] L. Xu, R. Baldick, and Y. Sutjandra, "TransmissionConstrained Inverse Residual Demand Jacobian Matrix in Electricity Markets," IEEE Trans. Power Syst., vol. 26, no. 4, pp. 2311-2318, 2009.

[7] F. A. Wolak, "Measuring Unilateral Market Power in Wholesale Electricity Markets: The California Market, 1998-2000," Am. Econ. Rev., vol. 93, no. 2, pp. 425-430, May 2003.

[8] S. D. McRae and F. A. Wolak, "How Do Firms Exercise Uni- lateral Market Power? Evidence From a Bid-Based Wholesale Electricity Market," 2009.

[9] V. Marques, I. Soares, and A. Fortunato, "Measuring market power in the wholesale electricity Iberian market through the residual demand curve elasticity," in Electricity Market, 2008. ..., 2008, no. 1, pp. 1-7.

[10]"Alberta Electric System Operator (AESO). [Online]. Available: http://www.aeso.ca/.” . 